\title{
Bilateral tubal pregnancy: A diagnostic dilemma
}

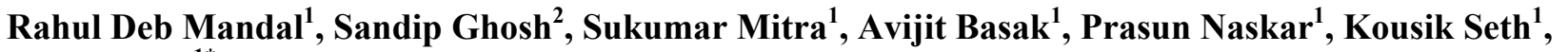 \\ Atin Halder ${ }^{1^{*}}$ \\ ${ }^{1}$ Department of Gynecology and Obstetrics, Burdwan Medical College, Burdwan, India \\ ${ }^{2}$ Department of General Surgery, Burdwan Medical College, Burdwan, India \\ Email: ${ }^{*}$ atin_halder@yahoo.co.in
}

Received 20 June 2013; revised 18 July 2013; accepted 26 July 2013

Copyright (C) 2013 Rahul Deb Mandal et al. This is an open access article distributed under the Creative Commons Attribution License, which permits unrestricted use, distribution, and reproduction in any medium, provided the original work is properly cited.

\begin{abstract}
Bilateral tubal ectopic pregnancy is very rare and usually occurs following ovulation stimulation. Moreover preoperative diagnosis is very difficult. We are presenting a case of bilateral tubal ectopic pregnancy occurring spontaneously. Hence careful follow-up with combination of color Doppler and serum beta HCG estimation of patients after laparoscopic or open surgery for ectopic pregnancies is needed to avoid such unusual event.
\end{abstract}

Keywords: Bilateral; Tubal Ectopic; Diagnostic Dilemma; Colourdoppler

\section{INTRODUCTION}

Ruptured extra-uterine pregnancy is still an important cause of maternal mortality. $97 \%$ of extra-uterine pregnancy is tubal. Unilateral tubal ectopic pregnancy is common but bilateral tubal ectopic pregnancy is very rare, and usually follows ovulation stimulation. There are no cases reported in which preoperative diagnosis of bilateral ectopic pregnancy was made [1]. The case reported here has occurred spontaneously.

\section{CASE REPORT}

A 32-year-old mother Gravida 3, Para 2 presented with 2 months amenorrhea followed by bleeding per vagina and pain in the lower abdomen since 2 days. She had bilateral tubal ligation 13 years back. Her past menstrual cycles were regular. She had tachycardia (110 per minute), hypotension (blood pressure of 90/50 $\mathrm{mm} \mathrm{Hg}$ ) and severe pallor at the time of admission. Abdominopelvic examination revealed tenderness in the lower abdomen, tender cervical movements, palpable tender right adnexal mass and fullness in all the fornices. There was haemoperito-

\footnotetext{
*Corresponding author.
}

neum on colpopuncture. Emergency exploratory laparotomy was performed. Haemoperitoneum of approximately $400 \mathrm{ml}$ was present. On the right side, there was a ruptured tubal ectopic pregnancy, and the patient was bleeding from this site (Figure 1). The left tube showed an organized hematoma of $2 \times 3 \mathrm{~cm}$ size, protruding from the tubal ostium and fixed posterior to uterus (Figure 1). That was not bleeding, suggestive of an ectopic pregnancy in the process of abortion. In view of these findings, both sided salpingectomy was done and both tubes were sent for histopathology. The patient recovered uneventfully and was discharged on the 7th post-operative day. Histopathology of the specimens showing chorionic villi and trophoblasts in both tubes confirmed the diagnosis of bilateral tubal ectopic (Figures 2 and 3).

\section{DISCUSSION}

Incidence of bilateral ectopic is thought to be somewhere between 1 in 125 and 1 in 1580 extrauterine pregnancies [2]. More than 200 cases of bilateral tubal ectopic pregnancy have been reported in the literature to date [3].

Various theories that include twining, superfetation and second pregnancy following tubal abortion of first one have been put forward to explain its occurrence $[4,5]$. Thankfully after a century of rapid technological advances, the diagnosis and management of ectopic have been dramatically improved. But bilateral ectopic pregnancy is difficult to diagnose preoperatively, indicating limitations of ultrasonography [6]. A high index of suspicion for pregnancy despite a history of bilateral salpingectomies in a woman of reproductive age presenting with a period of amenorrhoea is thus prudent in order to avoid missing an ectopic. Laparoscopy remains the main cornerstone of diagnosis and treatment in majority of women especially true in bilateral tubal pregnancy because of its conservative approach and the patient recovers more quickly [7].

Moreover a case has been reported in which consecu- 


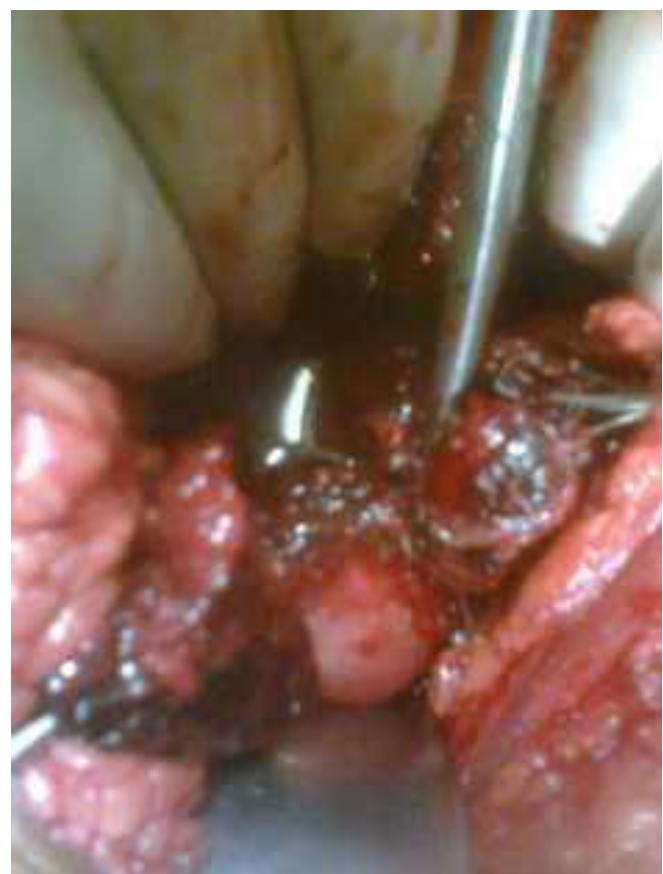

Figure 1. On the right side, there was a ruptured tubal ectopic pregnancy, and the left tube showed an organized hematoma of $2 \times 3 \mathrm{~cm}$ size, protruding from the tubal ostium.

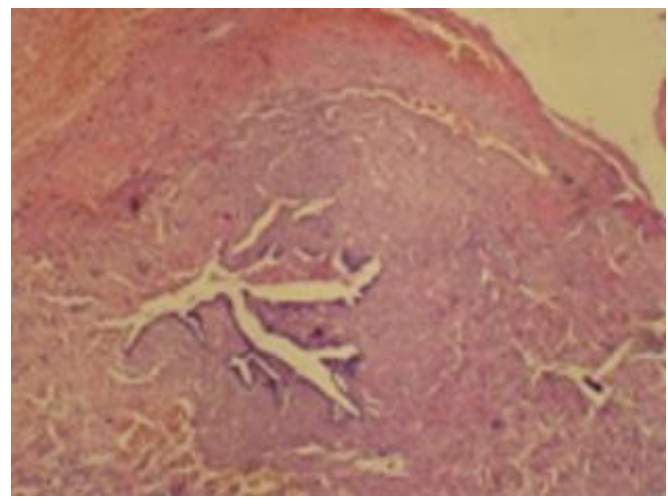

Figure 2. Histopathology of right tube showing chorionic villi and trophoblasts.

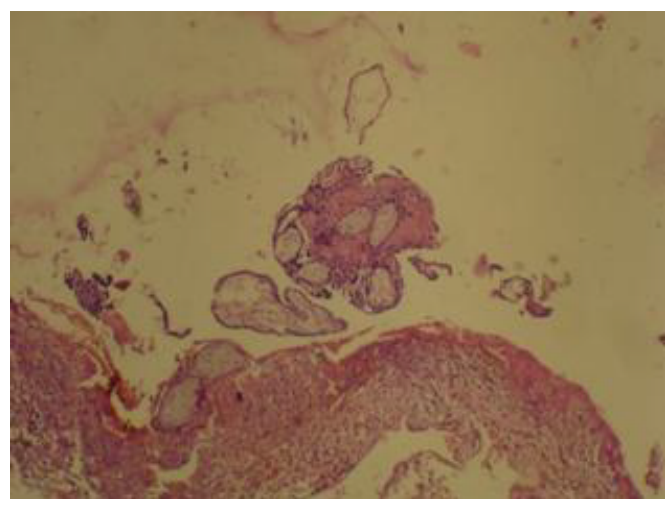

Figure 3. Histopathology of left tube showing chorionic villi. tive right and left salpingectomy were performed in seven weeks gap for ruptured ectopic despite left tube appeared normal during first surgery and the patient did not have coitus between the two salpingectomies [8]. Hence failure to recognize bilateral tubal ectopic even intra-operatively arises worsening of conditions.

Colour Doppler capacities further enhance the diagnostic sensitivity of transvaginal ultrasound for the early recognition of abnormal and normal intrauterine pregnancy, and small extrauterine masses preoperatively [6].

Careful attention should be directed to follow-up tests. A serial measurement of serum concentrations of human chorionic gonadotrophin is necessary to rule out the risk of persistent trophoblast until complete resolution is necessary [9].

Our patient, because of her acute symptoms, was not suitable for either laparoscopic surgery or medical management. At the time of surgery, examination of the contralateral tube governs treatment [4].

\section{CONCLUSION}

Hence we give emphasis not only to look at both adnexas during surgery for ectopic pregnancy but also to the careful follow-up with combination of color Doppler and serum beta HCG estimation of patients after laparoscopic or open surgery for ectopic pregnancies.

\section{REFERENCES}

[1] Phupong, V., Taneepanichskul, S. and Rungruxsirivorn, T. (2002) Bilateral tubal pregnancies after tubal sterilization in a human immunodeficiency virus seropositive woman. Journal of the Medical Association of Thailand, 85, 1236-1239.

[2] Adair, C.D., Benrubi, G.I., Sanchez-Ramos, L. and Rhatigan, R. (1994) Bilateral tubal ectopic pregnancies after bilateral partial salpingectomy. A case report. Journal of Reproductive Medicine, 39, 131.

[3] Abramovici, D., Morfesis, F.A., Ally, S. and Bathija, N.R. (1995) Bilateral ectopic pregnancy. A case report. The Journal of the Kentucky Medical Association, 93, 295.

[4] Tabachnikoff, R.M., Dada, M.O., Woods, R.J., Rohere, D. and Mayer, C.P. (1998) Bilateral ectopic pregnancy A report of an unusual cases. The Journal of Reproductive Medicine, 453, 707-709.

[5] Kobayashi, F., Sagawa, N., Konishi, I., Tsuruta, K., Fujiwara, H. and Mori, T. (1996) Spontaneous conception and intrautrrine pregnancy in a symptomatic missed abortion of ectopic pregnancy conceived in the previous cycle. Human Reproduction, 11, 134-139.

http://dx.doi.org/10.1093/oxfordjournals.humrep.a019385

[6] Goes, E., Breucq, C. and Osteaux, M. (1998) Ultrasound studies in ectopic pregnancies. Journal Belge de Radiologie, 81, 14-16.

[7] Hajenius, P.J., Mol, B.W.J., Bossuyt, P.M.M., Ankum, 
W.M. and Van der Veen, F. (2007) Interventions for tubal ectopic pregnancy. Cochrane Database of Systematic Reviews, 24, CD000324

[8] Tabachnikoff, R.M., Dada, M.O., Woods, R.J., Rohere, D. and Myers, C.P. (1998) Bilateral tubal pregnancy. A report of an unusual case. The Journal of Reproductive
Medicine, 43, 707-709.

[9] Al-Quraan, G.A., Al-Taani, M.I., Nusair, B.M., El-Masri, A., Arafat, M.R. and Khateeb, M.M. (2007) Spontaneous ruptured and intact bilateral tubal ectopic pregnancy, Eastern Mediterranean Health Journal, 13, 972-974. 